\title{
Concentrations of phenol, $o$-cresol, and 2,5-xylenol in the urine of workers employed in the distillation of the phenolic fraction of tar
}

\author{
Grażyna Bieniek
}

\begin{abstract}
Phenol (87.3 mg/n), p-cresol (58.6 mg/), o-cresol (76.9 mg/l), and 2,5-xylenol (36.7 mg/1) were detected in the urine of workers employed in the distillation of the high temperature phenolic fraction of tar (carbolic oil). The concentrations of these compounds in the urine of nonexposed male workers was $11.7 \mathrm{mg} / 1,25 \cdot 7$ $\mathrm{mg} / \mathrm{h}, 68 \cdot 1 \mu \mathrm{g} /$, and $69 \mu \mathrm{g} / \mathrm{respectively.}$ The excretion rates were $4.20 \mathrm{mg} / \mathrm{h}$ for phenol, $2.4 \mathrm{mg} / \mathrm{h}$ for $p$-cresol, $3.3 \mathrm{mg} / \mathrm{h}$ for o-cresol; and $1.5 \mathrm{mg} / \mathrm{h}$ for 2,5-xylenol. The highest concentrations of the mentioned compounds were detected in urine collected between eight and 10 hours from the beginning of exposure. The kinetics of excretion are considered.
\end{abstract}

(Occup Environ Med 1994;51:354-356)

Phenol is a normal constitutent of human urine $^{12}$ and concentrations above the physiological level have been found in the urine of people that have contact with benzene ${ }^{1-4}$ or phenol..$^{56} p$-Cresol also occurs in the urine of non-exposed people and its concentration can reach $50 \mathrm{mg} / \mathrm{l}^{7}$ Small amounts of 0 -cresol have been detected in the urine of workers in contact with toluene. ${ }^{8-12}$

After exposure to p-xylene, 2,5-xylenol was found in urine. ${ }^{13}$

Because high concentrations of $o$-cresol and 2,5-xylenol were found in hydrolysates of urine from workers in a carbochemical plant, measurement of excretion of these compounds in successive portions of urine collected during 24 hours was undertaken.

Materials and methods

The investigation was carried out on 106 male workers employed in the distillation of the high temperature phenolic fraction of tar (carbolic oil) and exposed mainly to phenol, cresols, xylenols, and other phenolic derivatives. Control urine specimens were collected from 26 male subjects not exposed professionally to phenol, cresols, or xylenols. All men were smokers.

\section{URINE SAMPLING}

Urine samples were collected as follows: (1) voids collected after four hours at work (examined directly after the and of the work shift) from exposed male workers and nonexposed subjects. (2) Successive voids, collected for 24 hours from 16 exposed male workers.

\section{URINE ANALYSIS}

The concentrations of phenol, p-cresol, $o$-cresol, and 2,5-xylenol in the hydrolysate of urine were determined spectrophotometrically after separation by means of thin layer chromatography on polyamide gel with the developing solvent chloroform-methanol (99:1 $\mathrm{v} / \mathrm{v}) .^{14}$ The concentrations were corrected for a specific gravity of 1.024 and for creatinine concentration in the urine.

Because of the low concentrations of $o$-cresol and 2,5-xylenol in urine of occupationally non-exposed workers, gas chromatographic techniques were used for these compounds.

\section{STATISTICS}

Geometric mean and geometric SD were calculated. Toxicokinetic calculations were made according to the methods of Piotrowski. ${ }^{15}$

\section{Results}

The metabolite concentrations were assumed to distribute $\log$ normally. Table 1 gives the concentrations of phenol, $p$-cresol, $o$-cresol,

Table Concentration and excretion rate of phenol, p-cresol, o-cresol, and 2,5-xylenol in urine

\begin{tabular}{|c|c|c|c|c|c|c|}
\hline \multirow{2}{*}{$\begin{array}{l}\text { Urinary } \\
\text { metabolite }\end{array}$} & \multirow[b]{2}{*}{ Group } & \multirow{2}{*}{$\begin{array}{l}\text { No of } \\
\text { subjects }\end{array}$} & \multirow{2}{*}{$\begin{array}{l}\text { Observed value } \\
\text { (mg/l) }\end{array}$} & \multicolumn{2}{|l|}{ Value corrected for } & \multirow{2}{*}{$\begin{array}{l}\text { Excretion rate } \\
(\mathrm{mg} / \mathrm{h})\end{array}$} \\
\hline & & & & Creatinine (mg/g) & Specific gravity* $^{*}(m g / l)$ & \\
\hline $\begin{array}{l}\text { Phenol } \\
\text { p-cresol } \\
\text { o-cresol } \\
\text { 2,5-Xylenol }\end{array}$ & $\begin{array}{l}\mathbf{A} \\
\mathbf{B} \\
\mathbf{A} \\
\mathbf{B} \\
\mathbf{A} \\
\mathbf{B} \\
\mathbf{A} \\
\mathbf{B}\end{array}$ & $\begin{array}{r}89 \\
26 \\
106 \\
26 \\
77 \\
24 \\
64 \\
15\end{array}$ & $\begin{array}{l}67 \cdot 8(2.483) \\
13.8(1.604) \\
54.3(1.722) \\
28.2(1.514) \\
58.9(3.031) \\
75.0(1.684) \dagger \\
30.4(2.775) \\
79.1(2.636) \dagger\end{array}$ & $\begin{array}{l}38 \cdot 2(2.212) \\
8 \cdot 3(1.531) \\
32.5(1.784) \\
17.8(1.515) \\
38.8(2 \cdot 243) \\
62 \cdot 2(1.594) \dagger \\
17.4(1.720) \\
54.5(2.366) \dagger\end{array}$ & $\begin{array}{l}87.3(2 \cdot 182) \\
11.7(1.486) \\
58.6(1.841) \\
25.7(1.430) \\
76.9(1.614) \\
68 \cdot 1(1.567) \dagger \\
36.7(1.614) \\
69.0(2 \cdot 178) \dagger\end{array}$ & $\begin{array}{l}4.20(2.281) \\
0.53(1.876) \\
2.43(2.064) \\
1.32(1.785) \\
3.31(2.204) \\
3.75(2.862) \dagger \\
1.50(1.794) \\
3.92(2.263) \dagger\end{array}$ \\
\hline
\end{tabular}

Values are geometric means (geometric SD); $A=$ workers employed in the distillation of carbolic oil; $B=$ non-exposed male workers.

*Specific gravity of urine 1.024

†Values in $\mu \mathrm{g} / \mathrm{l}, \mu \mathrm{g} / \mathrm{g}, \mu \mathrm{g} / \mathrm{l}$, and $\mu \mathrm{g} / \mathrm{h}$ for $\sigma$-cresol and 2,5 -xylenol in non-exposed workers.

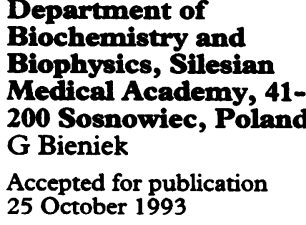

25 October 1993 
and 2,5-xylenol in the four hour samples of urine from the workers and non-exposed subjects.

The necessity to use hydrolysates of urine is evidence that the compounds are excreted in urine in the form of conjugates, probably as glucuronides and sulphates.

In 16 workers employed in the distillation of carbolic oil, the excretion of phenol, 0 -cresol, and 2,5-xylenol in successive voids of urine collected during 24 hours was determined. The highest concentrations of phenolic compounds were found during the first two hours after the end of the work shift.

The urinary excretion of phenol, o-cresol, and 2,5-xylenol as a function of time from the beginning of exposure was examined mathematically. The elimination of phenol, o-cresol, and 2,5-xylenol in the urine of workers can be described by the equations shown in the figure.

Because of considerable fluctuations in the concentration of $p$-cresol in urine of nonexposed persons, the excretion of $p$-cresol has not been considered here.

Urinary excretion as a function of time. $(A)$ phenol; regression equation for $t \leqslant 8 \cdot 8, c(t)=105$ for $t \leqslant 8 \cdot 8, c(t)=105$ $c(t)=105$ $\left(1-e^{-0.16(t+1)}\right) e^{-0.16(t-8.8)}$; $k=0 \cdot 16 / h, t_{1 / 2}=4 \cdot 3$ hours. (B) o-Cresol; regression equation for $t \leqslant 8 \cdot 8, o(t)=62.68$ $\left(1-e^{-0.34(t-1)}\right) ;$ for $t>8 \cdot 8$, $c(t)=62.68\left(1-e^{-0.34(t-1)}\right)$ $\left.e^{-0.34(t-8.8)}\right) ; k=0.34 / h, t_{1 / 2}$ $=2.0$ hours.

(C) 2,5-Xylenol; regression equation for $t \leqslant 8 \cdot 4, c(t)$ $=85.6\left(1-e^{-0.23 t}\right) ;$ for $t>$ $8.4, c(t)=85.6\left(1-e^{-0.23 t}\right)$ $e^{-0.23(t-8.4)} ; k=0.23 / h t_{1 / 2}=$ 3.0 hours.

$c=$ concentration of compounds in urine; $t=$ time from start of exposure. Note: o-cresol and

2,5-xylenol were not found in some urine samples in which phenol was found. Hence there are fewer points on graphs $B$ and $C$ than on graph $A$.
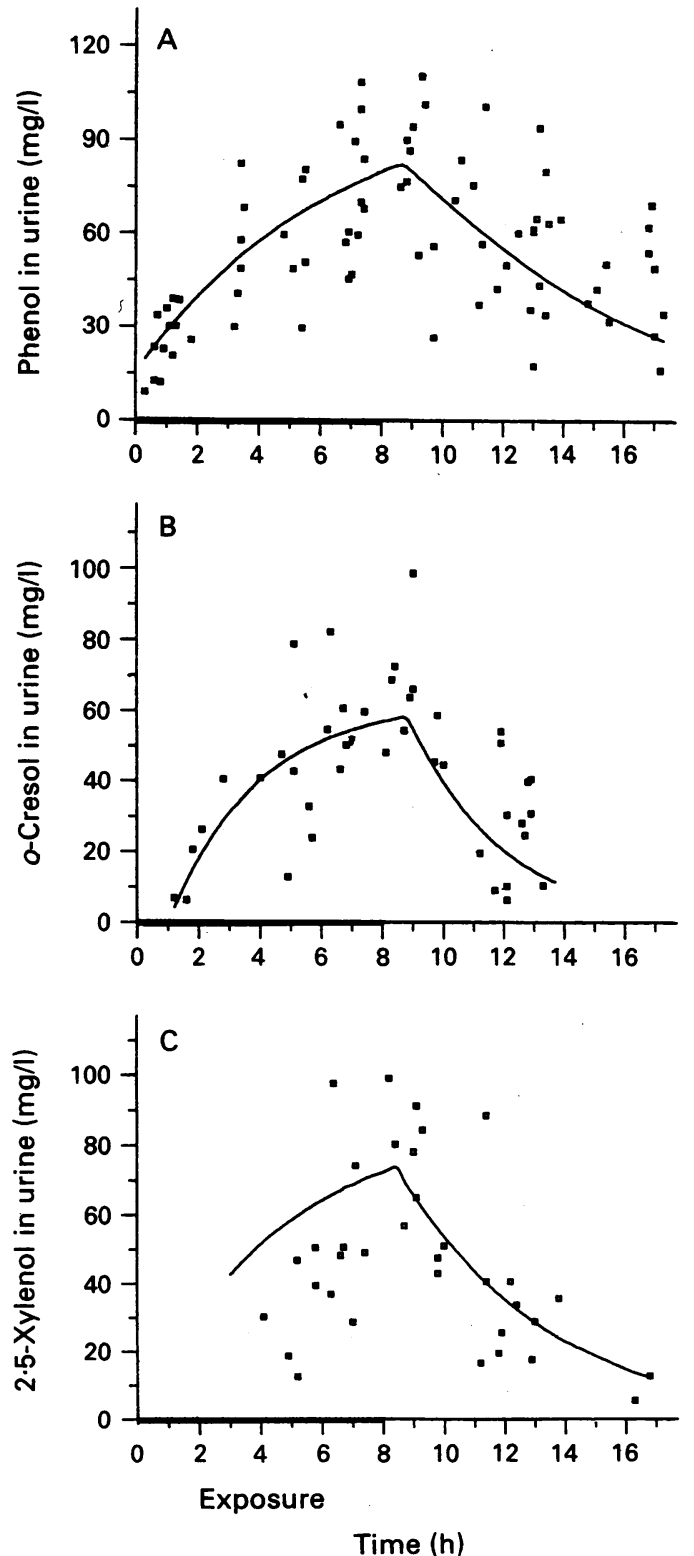

\section{Discussion}

Considerable differences in the concentration of vapours of phenolic compounds at various sites of the work area, difficulties in defining time of the exposure of particular workers, and likely absorption of phenolic compounds through the skin are reasons why measurement of the mean metabolite concentration in the urine seems to offer the most rational solution for realistic estimation of exposure.

Technologically processed carbolic oil contains phenol (14\%), o-cresol (4.8\%), and 2,4 and 2,5 -xylenol $(1 \cdot 8 \%)$. High values for concentrations of phenol, 0 -cresol, and 2,5xylenol in the urine confirm that exposure to these compounds occurred. Because o-cresol has been detected in the urine of persons having contact with toluene ${ }^{8-12}$ high concentrations of 0 -cresol in the urine of the workers might be the result of their exposure to both toluene and $o$-cresol present at the workplace.

For technical reasons, the data on urinary concentration of the phenolic compounds are not accompanied in this series of investigations by counterpart data on their concentrations in the air of the work premises. The data suggest, however, that in the absence of data on air concentrations, the determination of phenolic compounds in the urine may be valid as a comparative test of exposure.

The similar shape of the excretion curves presented in the figure suggests similarities in the metabolism of these phenolic compounds.

The phenol, o-cresol, and 2,5-xylenol excretion curves found under conditions of exposure in a carbochemical plant are similar to the curve obtained by Piotrowski ${ }^{15}$ after experimental exposure of humans to phenol. With regard to phenol itself, the fit of the kinetic curve is only approximate. The real values suggest a more prolonged process of elimination, a phenomenon discussed earlier by Paradowski ${ }^{2}$ in the case of workers with longstanding exposure to aromatic compounds. Such prolonged excretion does not occur in volunteers not previously exposed to aromatic compounds (unpublished data). With this reservation in mind the studied phenolic compounds are characterised by high turnover rates, which principally exclude their possible accumulation in the course of subsequent days of exposure.

The kinetic results presented here show that phenol, $o$-cresol, and 2,5-xylenol are quickly excreted into the urine. Thus the results of the biological monitoring relate to exposure on the day of urine collection rather than on the preceding days.

I thank Professor JK Piotrowski for his assistance in kinetic calculations, and Professor T Wilczok for supervising the work. I am grateful to $\mathrm{K}$ Klimek MS for her help with statistical analyses.

1 Dutkiewicz T. Evaluation of benzene exposure using the phenol test in industrial conditions. Med Pr 1965;16: 25-30. (In Polish.)

2 Paradowski M, Jakubowski M, Podoski M. Toxicokinetics of benzene in man: excretion of phenol in urine and of benzene with expired air after single and 4-d exposure to benzene. Med Pr 1984;35:85-96. (In Polish.) 
3 Yin S-G, Li G-L, Jin C, Cai S-X, Wang X-Z, Ikeda $M$ Quantitative relation of urinary phenol levels to breathzone benzene concentrations: a factory survey. $\mathrm{Br} \mathcal{F}$ Ind Med 1986;43:692-7.

4 Drummond L, Luck R, Safacan A, Wilson HK. Biological monitoring of workers exposed to benzene in the coke oven industry. Br $\mathcal{F}$ Ind Med 1988;45:256-61.

5 Piotrowski JK. Evaluation of exposure to phenol: absorption of phenol vapour in the lungs and through the skin and excretion of phenol in urine. $\mathrm{Br} \mathcal{F}$ Ind Med 1971; 28:172-8.

6 Ohtsuji M, Ikeda M. Quantitative relationship between atmospheric phenol vapour and phenol in the urine of workers in Bakelite factories. Br $\mathcal{F}$ Ind Med 1972;29. 70-3.

7 Angerer J. Chronische Losungsmittelbelastung am Arbeitsplatz. V: Chromatographische Methoden zur Bestimmung von Phenolen im Harn. Int Arch Occup Environ Health 1979;42:257-68.

8 Angerer J. Occupational chronic exposure to organic solvents. VII. Metabolism of toluene in man. Int Arch Occup Environ Health 1979;43:63-7.

9 Dossing M, Aelum JB, Hansen SH, Lundqvist GR Anderson NT. Urinary hippuric acid and orthocreso excretion in man during experimental exposure to toluene. Br f Ind Med 1983;40:470-3.

10 Hasagawa $K$, Shiozima S, Koizumi A, Ikeda M. Hippuric acid and $o$-cresol in the urine of workers exposed to toluene. Int Arch Occup Environ Health 1983;52 197-208.

11 Angerer J. Occupational chronic exposure to organic solvents XII. o-cresol excretion after toluene exposure. Int Arch Occup Environ Health 1985;56:323-8.

12 Nise G. Urinary excretion of o-cresol and hippuric acid after toluene exposure in rotogravure printing. Int Arch Occup Environ Health 1992;63:377-81.

13 Sedivec V, Flek J. The absorption, metabolism and excre tion of xylenes in man. Int Arch Occup Environ Health 1976;37:205-17.

14 Bieniek G, Wilczok T. Separation and determination of phenol, $\alpha$-naphthol, $m-, p$-, and, $o$-cresols and 2,5xylenol and catechol in the urine after mixed exposure to phenol, naphthalene, cresols, and xylenols. Br $\mathcal{Y}$ Ind Med 1986;43:570-1

15 Piotrowski JK. The application of metabolic and excretion kinetics to problems of industrial toxicology. Washington US Department of Health, Education and Welfare, 1971. 